\title{
Commentary: The transition from resident to attending is a marathon, not a sprint
}

\author{
Ikenna Okereke, MD
}

\author{
From the Division of Cardiothoracic Surgery, University of Texas Medical Branch, Galveston, Tex. \\ Disclosures: Author has nothing to disclose with regard to commercial support. \\ Received for publication Sept 22, 2019; revisions received Sept 22, 2019; accepted for publication Sept 23, 2019; \\ available ahead of print Oct 23, 2019. \\ Address for reprints: Ikenna Okereke, MD, Thoracic Surgery, University of Texas Medical Branch, 301 Univer- \\ sity Blvd, Galveston, TX 77555 (E-mail: ikokerek@utmb.edu) \\ J Thorac Cardiovasc Surg 2020;159:1161-2 \\ $0022-5223 / \$ 36.00$ \\ Copyright (C) 2019 by The American Association for Thoracic Surgery \\ https://doi.org/10.1016/j.jtcvs.2019.09.096
}

One of the most exciting yet anxious periods in the career of a cardiothoracic surgeon is the early time after finishing training. After anywhere from 6 to 10 years of residency training, there is a high level of enthusiasm and a desire to burst onto the scene. This eagerness must be coupled with prudence, however, to be successful. This article by Fiedler and Sihag ${ }^{1}$ addresses some of these strategies from the perspective of 2 young cardiothoracic surgeons.

One of the main obstacles for early cardiothoracic surgeons is the comfort they have when performing certain core cardiothoracic surgical procedures. Some studies have shown that only $50 \%$ of trainees feel that they have adequate or better experience with common thoracic procedures. ${ }^{2}$ Yet these early surgeons will be responsible for patients who require these procedures to be performed safely and correctly. It is important, as such, for the early surgeon to know when to call for help. It is always acceptable to ask for assistance on a case, and it should not be considered as a sign of weakness or failure. Although the formal fellowship and training may have ended, young surgeons will learn an incredible amount of detail and tips about how to operate in the early years after training. With time, the need to call for help will become less frequent while maintaining excellent patient outcomes.

Another important aspect of the first few years after training is the work-life balance. As my mentor told me when I was finishing fellowship, "You have less patients to manage. But you get a thousand more things on your plate." Committee assignments, studying for certifying examinations, writing grant applications, and other tasks can make the first few years after fellowship quite chaotic. It is important to maintain a structured schedule to be able to address all of these tasks adequately. Even though emergencies and unexpected events may potentially disrupt plans, creating a weekly calendar dedicating time to operating, studying, working on research, etc, will decrease the chaos to some extent. and successful.

\section{References} 68:270-81.

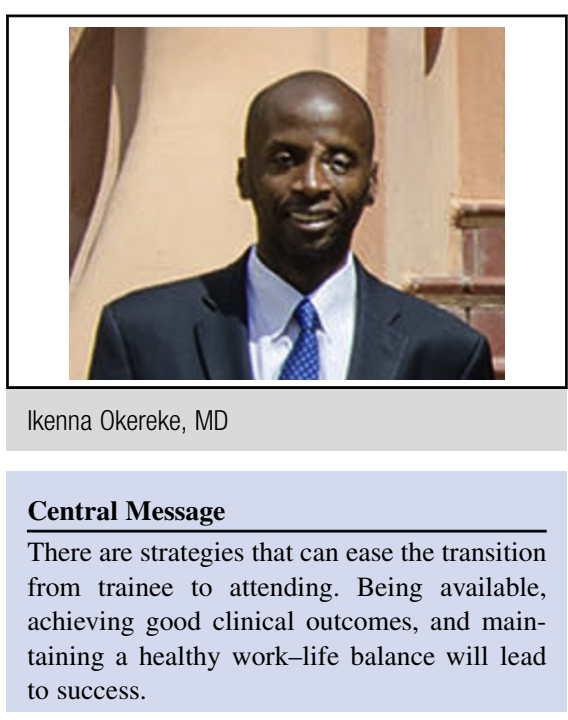

See Article page 1156.

When creating this weekly calendar, it is necessary that time is allotted for well-being. Increasingly surgeons are becoming aware of burnout. ${ }^{3}$ Although the emphasis placed on clinical productivity has intensified, all of the other responsibilities of an attending surgeon have remained. This phenomenon has led to rates of burnout as high as $81 \%$ and rates of emotional exhaustion as high as $86 \%$ among physicians. ${ }^{4}$ The young surgeon can be especially vulnerable to burnout, given that they are usually in a new hospital, new city, and probably do not have many social contacts. It is essential that healthy coping mechanisms are developed, and participation in activities outside the hospital is encouraged. These activities have been shown to reduce burnout rates ${ }^{5}$ and will likely make the young surgeon more efficient

The first few years after formal training ends is a wonderful dive into the unknown for every cardiothoracic surgeon. With proper organization and support, it will be quite fruitful for the young surgeon.

1. Fiedler AG, Sihag S. Entering the great unknown: transition to academic practice. J Thorac Cardiovasc Surg. 2020;159:1156-60.

2. Edwards J, Kelly E, Schieman C, Gelfand G, Grondin S. Do new thoracic surgeons feel ready to operate? Self-reported comfort level of thoracic surgery trainees and junior thoracic surgeons with core thoracic surgery procedures. J Surg Educ. 2011;

3. Pulcrano M, Evans S, Sosin M. Quality of life and burnout rates across surgica specialties: a systematic review. JAMA Surg. 2016;151:970-8. 
4. Rotenstein L, Torre M, Ramos M, Rosales R, Guille C, Sen S, et al. Prevalence of burnout among physicians: a systematic review. JAMA. 2018;320: 1131-50.
5. Ireland M, Clough B, Gill K, Langan F, O'Connor A, Spencer L. A randomized controlled trial of mindfulness to reduce stress and burnout among intern medical practitioners. Med Teach. 2017;39:409-14. 